\title{
Heat-shock sigma factor RpoH from Geobacter sulfurreducens
}

\author{
Toshiyuki Ueki and Derek R. Lovley \\ Department of Microbiology, Morrill Science Center IV North, University of Massachusetts \\ Amherst, 639 North Pleasant Street, Amherst, MA 01003-9298, USA
}

Correspondence

Toshiyuki Ueki

tueki@microbio.umass.edu

Received 31 July 2006

Revised 10 November 2006

Accepted 23 November 2006

\section{INTRODUCTION}

The Gram-negative $\delta$-proteobacterium Geobacter sulfurreducens is considered to be a representative of the Fe(III)reducing Geobacteraceae that predominate in a diversity of subsurface environments where $\mathrm{Fe}(\mathrm{III})$ reduction is important (Lovley et al., 2004). Geobacter species also play critical roles in bioremediation of groundwater contaminated with organic compounds or metals (Lloyd \& Lovley, 2001; Lovley, 1997, 2003; Lovley \& Coates, 1997, 2000) and in electricity production from waste organic matter (Bond et al., 2002; Bond \& Lovley, 2003; Lovley, 2006a, b). However, the mechanisms they use to deal with the multiple stresses they encounter in these environments are poorly understood.

Geobacter species face various environmental changes and growth conditions in the subsurface. Heat shock is a common stress to which all organisms adapt by inducing heat-shock proteins. Many heat-shock proteins are well conserved among organisms (Arrigo \& Iandry, 1994; Lindquist \& Craig, 1998). In bacteria, the expression of heat-shock genes is regulated in various fashions (Gross,

\footnotetext{
Abbreviations: CIRCE, controlling inverted repeat of chaperone expression; RNAP, RNA polymerase.

The GenBank/EMBL/DDBJ accession number for the sequence reported in this paper is AAR33985.
}

1996; Hecker et al., 1996; Narberhaus, 1999; Rosen \& Ron, 2002; Schumann, 2000, 2003; Servant \& Mazodier, 2001; Yura et al., 2000). The Gram-negative bacterium Escherichia coli uses two sigma factors, $\mathrm{RpoH}$ and $\mathrm{RpoE}$, to activate transcription of heat-shock genes (Gross, 1996; Yura et al., 2000). The sigma factor, which is a subunit of RNA polymerase (RNAP), recognizes specific promoter elements and is essential for initiation of transcription. RpoHdependent transcription is also found in other Gramnegative bacteria (Gross, 1996; Yura et al., 2000; Rosen \& Ron, 2002). The regulation of heat-shock gene expression in the Gram-positive bacterium Bacillus subtilis is rather complex (Hecker et al., 1996; Schumann, 2003). In the B. subtilis heat-shock response transcription of heat-shock genes is regulated by both activation via a sigma factor, SigB, and repression via two different transcription factors, HrcA and CtsR. Both HrcA and CtsR repressors are also found in other bacteria (Narberhaus, 1999; Rosen \& Ron, 2002). Other repressor proteins, HspR and RheA, have been shown to be involved in heat-shock gene expression in some bacteria (Servant \& Mazodier, 2001).

The heat-shock response in $\delta$-Proteobacteria is poorly understood. Myxococcus xanthus has three homologues of RpoH (Ueki \& Inouye, 2001). However, these homologues were shown to be dispensable for the production of heatshock proteins and adaptation to heat shock, and instead to be involved in multicellular development in $M$. xanthus 
(Ueki \& Inouye, 2001). In contrast, Desulfovibrio vulgaris has a single homologue of $\mathrm{RpoH}$, and several heat-shock genes were predicted to have $\mathrm{RpoH}$-dependent promoters (Chhabra et al., 2006).

The G. sulfurreducens genome contains homologues of the sigma factor genes $r p o D, r p o S, r p o H, r p o E$, fliA and $r p o N$ (Methé et al., 2003). In this study, we characterized the role of the $r p o H$ homologue in the heat-shock response of the model organism G. sulfurreducens in order to understand the stress responses utilized by Geobacter communities in the subsurface. Our results indicate that G. sulfurreducens $\mathrm{RpoH}$ is indeed the heat-shock sigma factor. In addition, it is likely that the HrcA/CIRCE system is also involved in the G. sulfurreducens heat-shock response.

\section{METHODS}

Bacterial strains and growth conditions. G. sulfurreducens DL1 (Caccavo et al., 1994) was used as the parent (wild-type) strain for the construction of the rpoH mutant. G. sulfurreducens strains were grown anaerobically in NBAF (acetate and fumarate as an electron donor and an acceptor, respectively) medium (Coppi et al., 2001), supplemented with appropriate antibiotics when necessary. E. coli DH5 $\alpha$ (Hanahan, 1983) was used for plasmid preparation and grown in LB medium (Miller, 1972), supplemented with appropriate antibiotics when necessary.

Construction of the rpoH mutant. The gene encoding $\mathrm{RpoH}$ was replaced with a kanamycin-resistance gene, such that the coding region for amino acid residues from Ile-19 to Leu-208 was deleted. Double-crossover homologous recombination was carried out by electroporation (Coppi et al., 2001) with the linear DNA fragment consisting of the kanamycin-resistance gene flanked by $0.7 \mathrm{~kb}$ DNA fragments containing the upstream and the downstream regions of $r p o H$. These flanking DNA fragments were amplified by PCR with primer 5'-TCTCTAGATGCCGCCGATGAAAAGATC-3' and 5'TCGAATTCTCTCAGGTAGACGGTAAGGC-3' (XbaI and EcoRI sites are underlined), and 5'-TCAAGCTTCCAAGAGTCCGAGTTGCTC- ${ }^{\prime}$ and $5^{\prime}$-TCGGATCCGGACGCACGCGTCGTTGATC-3' (HindIII and BamHI sites are underlined), respectively. The DNA fragment of the kanamycin-resistance gene was amplified by PCR with primers 5'-GCATGAGAATTCCTGACGGAACAGCGGGAAGTCCAGC-3' and 5'-GCTATGAAGCTTTCATAGAAGGCGGCGGTGGAATCGAA-3' (EcoRI and HindIII sites are underlined), and pBBR1MCS-2 (Kovach et al., 1994) as a template. The replacement was confirmed by PCR amplification.

Construction of the expression vector for $\boldsymbol{r p o H}$. The DNA fragment containing the $286 \mathrm{bp}$ upstream region of the initiation codon of $\mathrm{RpoH}$, the coding region of $\mathrm{RpoH}$, and the $102 \mathrm{bp}$ downstream region of the termination codon of $\mathrm{RpoH}$ including the putative transcription termination signal was amplified by PCR with primers $5^{\prime}$-TCAAGCTTCTTCAGGACCTCCGTTAGCC-3' and $5^{\prime}$ TCGAATTCATATCGCTCTTGTTGATCAC-3' (HindIII and EcoRI sites are underlined). The spectinomycin-resistance gene was amplified with pSJS985Q (Sandler \& Clark, 1994) as a template and primers $5^{\prime}$-TCGAATTCACAGGATGACGCCTAAC- ${ }^{\prime}$ and $5^{\prime}$-TCCTCGAGTCTAACGCTTGAGTTAA-3' (EcoRI and Xhol sites are underlined). The HindIII-EcoRI fragment of the $r p o H$ gene and the EcoRI-XhoI fragment of the spectinomycin-resistance gene were cloned into the XhoI-HindIII fragment from pCM66 (Marx \& Lidstrom, 2001). The resultant plasmid was introduced into the rpoH mutant by electroporation (Coppi et al., 2001).
Primer extension assays. G. sulfurreducens DL1 (wild-type) and $\mathrm{rpoH}$ mutant strains were grown at $30^{\circ} \mathrm{C}$ before heat shock. Total RNA was prepared before and after heat shock at $42^{\circ} \mathrm{C}$ for $10 \mathrm{~min}$. The primers used in the assays were $5^{\prime}$-TTCTCTCAGGTAGACGGTAAGGC-3' $(r p o H), \quad 5^{\prime}$-TCCTCGATGATGGCTTCGA-3' ( $h r c A), \quad 5^{\prime}$-CCGCGATGGTTTCATCTGCAC-3' (grpE), 5'-TCCATAACAGCAACGCAGGA-3' (dnaK), 5'-CCAGGAGCTGCTGGACTTC-3' (htpG), and 5'-CGGTCTTGCAACGGTCTGAGATTC-3' (groES).

In vitro transcription. The coding region of G. sulfurreducens rpoH was amplified by PCR with primers $5^{\prime}$-TCTCATATGTCGATGAGCTTACCTGT- 3 ' and $5^{\prime}$-TCGAATTCTCA(GTG) ${ }_{8}$ GACCGGTCGCGTCTCTGCAA-3' (NdeI and EcoRI sites are underlined). The PCR products were cloned into pET24b (Novagen). G. sulfurreducens $\mathrm{RpoH}$ was prepared as a histidine-tagged protein at the C-terminus (see Fig. 5a). Expression and purification of RpoH were performed as described previously (Ueki \& Inouye, 2005). E. coli core RNAP and holo RNAP containing RpoD (RNAP/RpoD) were purchased from EPICENTRE Biotechnologies. Holo RNAP/RpoH was reconstituted by mixing E. coli core RNAP and G. sulfurreducens $\mathrm{RpoH}$ and incubating on ice for 15 min before the initiation of transcription reactions. Transcription reactions were conducted at $37^{\circ} \mathrm{C}$. The template contained the $\mathrm{rpoH}$ promoter region from nucleotides -238 to +42 with respect to the transcription initiation site. In vitro transcription reactions were carried out as described by Ueki \& Inouye (2002). The transcripts were analysed by a primer extension assay.

\section{RESULTS AND DISCUSSION}

\section{G. sulfurreducens RpoH}

The G. sulfurreducens genome contains a single rpoH homologue (GSU0655) (Methé et al., 2003). G. sulfurreducens RpoH shows similarity to RpoH homologues from other bacteria including G. metallireducens, Anaeromyxobacter dehalogenans and E. coli. In addition, G. sulfurreducens $\mathrm{RpoH}$ contains the sequence QKKLFFKLN, which is highly homologous to the 'RpoH box', a stretch of nine amino acid residues, $\mathrm{Q}(\mathrm{R} / \mathrm{K})(\mathrm{K} / \mathrm{R}) \mathrm{LFFNLR}$, that is only conserved in RpoH homologues (Nakahigashi et al., 1995).

To elucidate the function of the rpoH homologue in $G$. sulfurreducens, the expression of the $r p o H$ gene was examined by a primer extension assay (Fig. 1). rpoH mRNA was detected only in cells heat-shocked at $42^{\circ} \mathrm{C}$ for $10 \mathrm{~min}$ (Fig. 1a). A single $5^{\prime}$ end of the mRNA was detected and the putative $-35 /-10$ promoter elements were assigned (Fig. 1b). In addition, a sequence identical to the CIRCE (controlling inverted repeat of chaperon expression) consensus sequence (TTAGCACTC- $\mathrm{N}_{9}$-GAGTGCTAA), which is the operator sequence bound by $\mathrm{HrcA}$ in other bacteria (Narberhaus, 1999; Mogk et al., 1997; Schulz \& Schumann, 1996; Zuber \& Schumann, 1994), was found to be located in the rpoH promoter, indicating that $r p o H$ expression is regulated by $\mathrm{HrcA}$ as discussed below. It should be noted that a putative transcription termination signal is located downstream of the stop codon (Fig. 1c), indicating that the $r p o H$ gene is probably monocistronic. 
In order to examine the role of $r p o H$ in heat-shock response in G. sulfurreducens an rpoH mutant was constructed. The mutant grew normally in NBAF medium at $30^{\circ} \mathrm{C}$ (data not shown). However, the mutant was unable to adapt to an elevated growth temperature of $42^{\circ} \mathrm{C}$ (Fig. 2). The wild-type grew to an $\mathrm{OD}_{600}$ of approximately 0.8 after the temperature shift. In contrast, the mutant stopped growing at an $\mathrm{OD}_{600}$ of approximately 0.5 after the temperature shift and cell lysis was observed in the mutant culture. The plasmid containing the $r p o H$ gene allowed the $r p o H$ mutant to grow at $42{ }^{\circ} \mathrm{C}$ similarly to the wild-type, indicating that the defect in the adaptation of the $r p o H$ mutant was solely due to the absence of the $r p o H$ gene. These results suggest that the $r p o H$ gene is essential for adaptation to an elevated growth temperature in G. sulfurreducens.

\section{Expression of heat-shock genes}

To identify genes regulated by RpoH in G. sulfurreducens, the expression of genes known to be heat-shock inducible in other bacteria was investigated by primer extension assays (Fig. 3). G. sulfurreducens hrcA (Fig. 3a), grpE (Fig. 3b), dnaK (Fig. 3c), htpG (Fig. 3d), and groES (Fig. 3e) were induced by heat shock at $42^{\circ} \mathrm{C}$ for $10 \mathrm{~min}$. One $5^{\prime}$ end of $h t p G$ mRNA was detected, two $5^{\prime}$ ends of mRNA were detected for $h r c A$, $\operatorname{grp} E$ and $d n a K$, and three $5^{\prime}$ ends of groES mRNA were detected. The expression of these genes was dependent on the $r p o H$ gene, as it was undetectable or drastically decreased in the $r p o H$ mutant. Interestingly, groES mRNA was observed even before heat shock, although the expression level was low.
This suggests that groES and most likely groEL, which is located downstream of groES and appears to be cotranscribed with groES, are required at physiological temperatures. Molecular chaperonins such as the GroE system and molecular chaperones such as the DnaK/DnaJ/ GrpE and the HtpG systems are crucial to protein folding (Riggs et al., 2004; Young et al., 2004; Zhang et al., 2002). In addition, the GroE system is thought to activate the HrcA repressor (Mogk et al., 1997; Schumann, 2000).

The putative $-35 /-10$ promoter elements were assigned for these genes from an analysis of the $5^{\prime}$ ends identified by the primer extension assays (Fig. 3). A sequence identical to the CIRCE consensus sequence (Narberhaus, 1999) was found to be located in the hrcA promoter, indicating that HrcA represses the transcription of its own gene. Such autoregulation of $h r c A$ is also found in other bacteria, such as the $\varepsilon$-proteobacterium Helicobacter pylori (Spohn et al., 2004). In addition, the groES promoter contains a sequence identical to the CIRCE consensus sequence, as other groES promoters do in bacteria that utilize HrcA. The $-35 /-10$ elements in the hrcA P2, the grpE P2, the dnaK P2, the groES $\mathrm{P} 3$ and the $h t p G$ promoters show high similarity to one another and those in the rpoH promoter (Fig. 4a). The groES $\mathrm{P} 1$ promoter has $-35 /-10$ elements similar to those in the RpoD-dependent promoters, while the other promoters exhibit no apparent similarity to known promoters. These results indicate that these heat-shock genes and $r p o H$ are regulated by the $r p o H$ gene. Moreover, it is likely that the absence and/or the reduced expression of heat-shock genes (a)

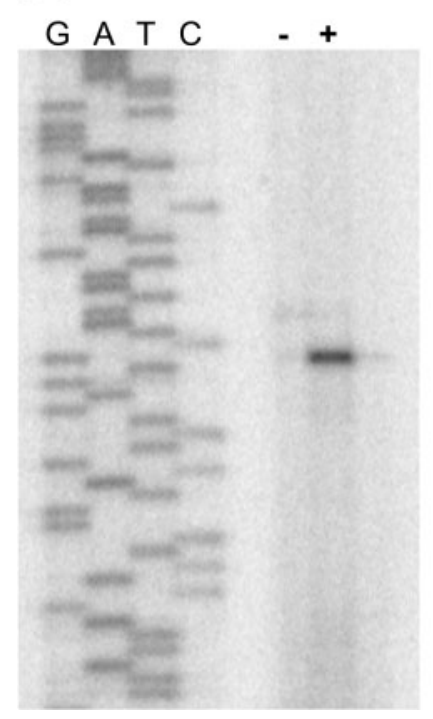

(b)

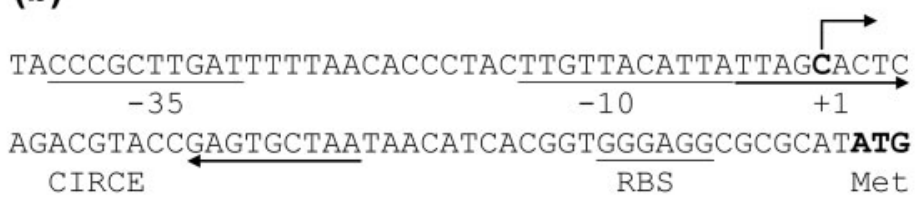

(c)

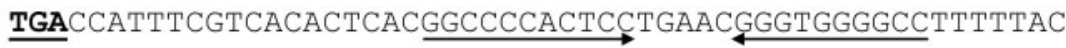

Fig. 1. Expression of the $r p o H$ gene. (a) Primer extension assay. Total RNA was prepared before $(-)$ and after $(+)$ heat shock. (b) The promoter region of the $r p o H$ gene. The $5^{\prime}$ end of the $r p o H$ mRNA identified in (a) is indicated by +1 . The putative -35 and -10 elements and putative ribosome-binding site (RBS) are underlined. The arrows indicate the putative CIRCE element. The initiation codon is indicated by Met. (c) The transcription termination of the rpoH gene. The arrows indicate the putative transcription termination signal. The stop codon is underlined. 


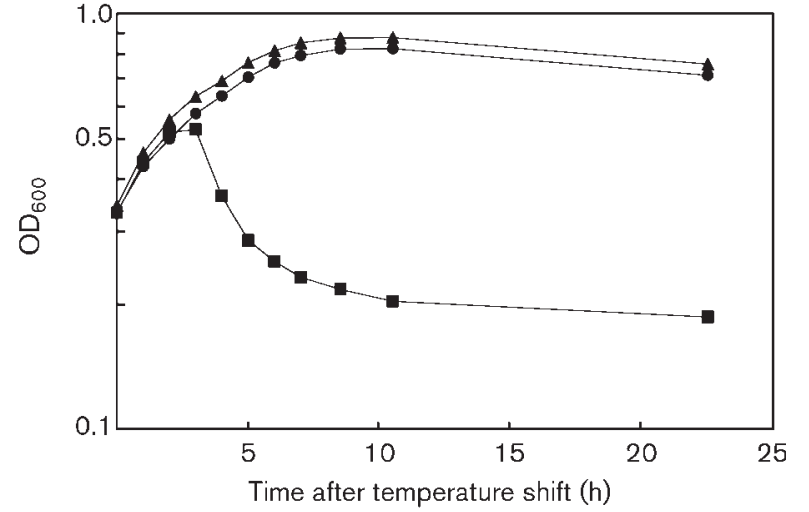

Fig. 2. Adaptation to a higher temperature. The wild-type (circles), the rpoH mutant (squares), and the rpoH mutant harbouring the plasmid containing the $\mathrm{rpoH}$ gene (triangles) were grown at $30{ }^{\circ} \mathrm{C}$ and then shifted to $42^{\circ} \mathrm{C}$. Growth was monitored as $\mathrm{OD}_{600}$.

caused by the lack of the $r p o H$ gene results in inadequate adaptation to the higher temperature.

The consensus sequences for the $-35 /-10$ promoter elements of heat-shock genes in G. sulfurreducens are proposed (Fig. 4a). The -35 element shows high similarity to that of the E. coli RpoH consensus recognition sequence (Gross, 1996; Yura et al., 2000), whereas the -10 element exhibits low similarity. This difference is supported by the extent of similarity in amino acid sequences of $\mathrm{RpoH}$ from G. sulfurreducens and E. coli (Fig. 4b). Region 4.2, which recognizes the -35 element, is highly similar between $G$. sulfurreducens and E. coli $\mathrm{RpoH}$ homologues, while region 2.4 , which recognizes the -10 element, is less conserved between G. sulfurreducens and E. coli RpoH homologues.

\section{The gene cluster containing hrcA, grpE, dnaK and dnaJ}

In G. sulfurreducens, $h r c A, g r p E$, dnaK and dnaJ are located in this order on the chromosome and appear to constitute an operon, because the lengths of intergenic regions between these genes are short (data not shown). A similar gene organization of these homologues is also found in other bacteria such as B. subtilis (Wetzstein et al., 1992). grpE is typically located downstream of $h r c A$ on the chromosome in bacteria that contain $h r c A$. Despite the proximity between $h r c A$ and $g r p E$, the transcription of $g r p E$ is often driven by its own promoter (Wetzstein et al., 1992; Narberhaus et al., 1992; Roberts et al., 1996). In contrast, the location of $d n a K$ and $d n a J$, which is usually located downstream of $d n a K$, is diversified. When located downstream of grpE, dnaK and dnaJ are co-transcribed with grpE (Wetzstein et al., 1992; Narberhaus et al., 1992). However, in G. sulfurreducens, not only grpE but also dnaK were individually transcribed (Fig. 3). It appears likely that $d n a J$ is co-transcribed with dnaK in G. sulfurreducens, as a $5^{\prime}$ end specific to dnaJ mRNA was not detected by a primer extension assay (data not shown). Separate transcription may facilitate more efficient expression of these genes than co-transcription, resulting in proper function of these genes during heat shock. However, it is possible that these genes can be both co-transcribed and individually transcribed under different conditions.

\section{Transcriptional regulation of $\mathrm{rpoH}$}

To investigate the transcriptional regulation of the $r p o H$ gene in G. sulfurreducens, in vitro transcription assays were conducted with the $r p o H$ promoter as a template (Fig. 5). The in vitro transcripts were analysed by primer extension assay to confirm that the $5^{\prime}$ end of the in vitro transcripts was the same as that of the in vivo transcripts. Holo RNAP/RpoH recognized the $r p o H$ promoter and initiated transcription in vitro from the same position as in vivo (Fig. 5b), indicating that RNAP/RpoH transcribes its own gene. Furthermore, it is likely that RNAP/RpoH initiates the transcription of the other heat-shock genes, as their expression was dependent on $r p o H$ and their promoter elements show high similarity to $r p o H$ promoter elements (Fig. 4a). Surprisingly, E. coli holo RNAP/RpoD also initiated transcription in vitro from the same position as in vivo, although it produced fewer transcripts than RNAP/RpoH. The regulation of $r p o H$ expression in vivo was further examined in the $\mathrm{rpoH}$ mutant (Fig. 5c). It was found that $r p o H$ expression was still induced by heat shock in the $r p o H$ mutant, although its expression level decreased. It should be noted that the $r p o H$ promoter region as well as the $5^{\prime}$ end of the coding region, to which the primer used in the primer extension assays hybridized, were not deleted in the $\mathrm{rpoH}$ mutant, allowing one to measure the $r p o H$ promoter activity in the $r p o H$ mutant. These results suggest that the $r p o H$ promoter is also recognized by RNAP/ RpoD and that RNAP/RpoD is capable of transcribing the $r p o H$ gene in the absence of RpoH. rpoD is known to be heatshock inducible in some bacteria such as E. coli (Taylor et al., 1984). Thus, it is possible that G. sulfurreducens rpoD is also heat-shock inducible and that the induction of RpoD is sufficient to account for transcription of $r p o H$ in the $r p o H$ mutant. The rpoH promoter region contains the sequences TTGATT and TACATT (Fig. 1b), which show similarity to the E. coli RpoD consensus sequences TTGACA and TATAAT, respectively (Harley \& Reynolds, 1987; Hawley \& McClure, 1983). In addition, the groES P1 promoter also contains the RpoD recognition sequence-like $-35 /-10$ elements, TTGATT and TATAGT, respectively, and groES expression dependent on the P1 promoter was still induced by heat shock in the rpoH mutant (Fig. 3e). These results further suggest that RpoD is involved in heat-shock response in G. sulfurreducens. However, it is also possible that instead of RpoD, RpoS is involved in their expression in G. sulfurreducens. RpoS is the stationary phase sigma factor involved in responses to various stresses including heat shock (Hengge-Aronis, 2002) and G. sulfurreducens possesses a homologue of RpoS (Núñez et al., 2004). Furthermore, RpoD and RpoS recognize similar $-35 /-10$ promoter elements (Yan et al., 2006). 
(a)

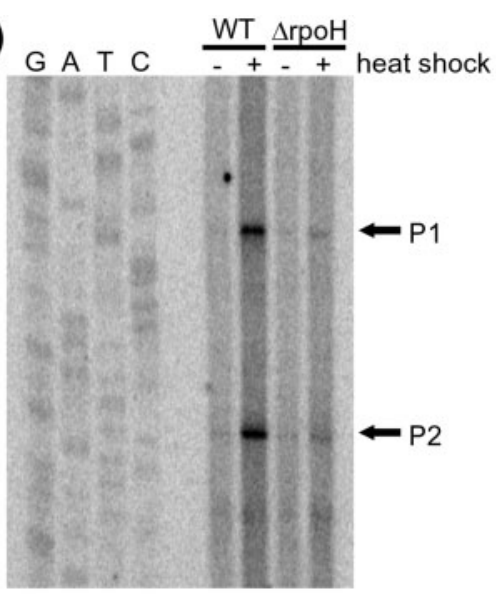

(b)

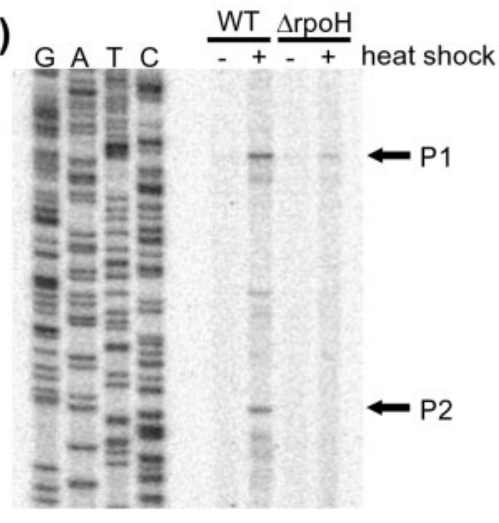

(c)

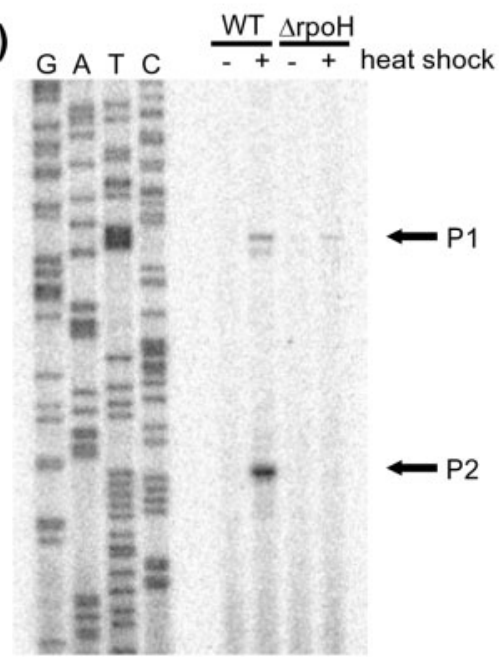

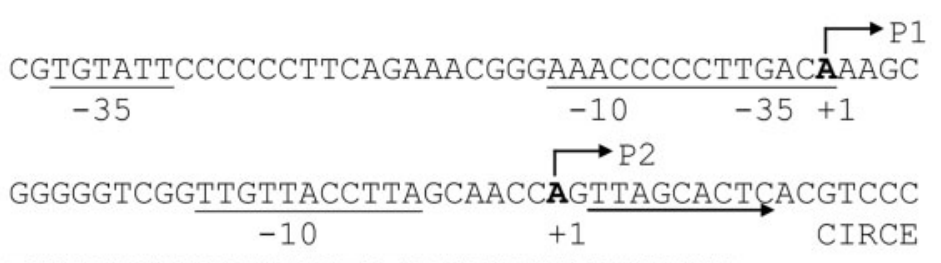

TTGAGTGCTAATCTGCTTTGTGGGGCCGAGAGATG

RBS Met $\frac{\text { GGTTTGAGCATCATCACCTCCACGTACCTCACGGGAAAGAACAC }}{-35}+\frac{\stackrel{\text { P1 }}{-10}+1}{+10}$

TCTCGGCGTTCTGGGGGTCATCGGACCGACCCGGATGGGCTATG

CCAAGGTGATCCCCATCGTCGACTATACCGCGAAGCTGGTCAGC

$\begin{array}{cc}\longrightarrow & -10 \\ \text { AGGCTCCTCGAAGGGGAATAGGAGCGGTTCGGCAGATATTCGCA }\end{array}$

$+1$

GGGAGGAACTATCAGCGTG

RBS Met

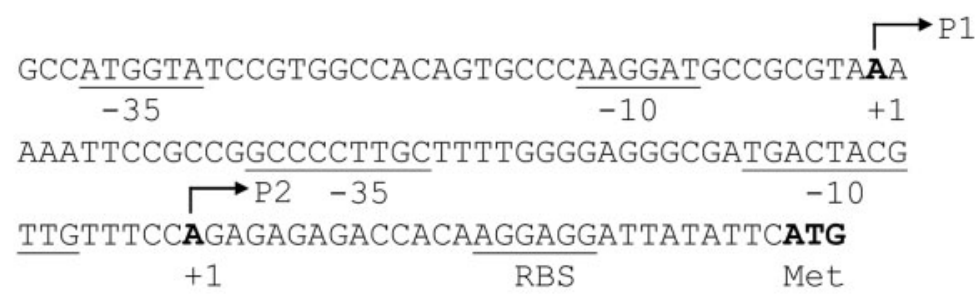

The expression of $\mathrm{RpoH}$ is mainly controlled at the level of translation in the Gram-negative $\gamma$-proteobacterium E. coli (Gross, 1996; Yura et al., 2000). Upon heat shock the cellular level of RpoH increases by both enhanced translation of $r p o H$ mRNA and stabilization of RpoH in E. coli. The $r p o H$ homologues from $\gamma$-Proteobacteria share common structural characteristics with E. coli rpoH, such as a downstream box, mRNA secondary structure and highly conserved amino acid sequence of region $\mathrm{C}$, all of which are important for thermoregulation of $r p o H$ translation and for stability and activity of RpoH in E. coli (Nakahigashi et al., 1995). In contrast, $\alpha$ - and $\beta$-Proteobacteria have diverged from $\gamma$ Proteobacteria in their mechanisms of regulation of $r p o H$ expression. $r p o H$ genes from $\alpha$ - and $\beta$-Proteobacteria do not contain characteristics found in those from $\gamma$-Proteobacteria. Instead, some rpoH genes from $\alpha$-Proteobacteria, such as Agrobacterium tumefaciens (Nakahigashi et al., 1999), Bradyrhizobium japonicum (Narberhaus et al., 1997) and Caulobacter crescentus (Reisenauer et al., 1996; Wu \& Newton, 1996), contain an RpoH-dependent promoter that can be induced by heat shock. In G. sulfurreducens the downstream box and mRNA secondary structure found in 
(d)

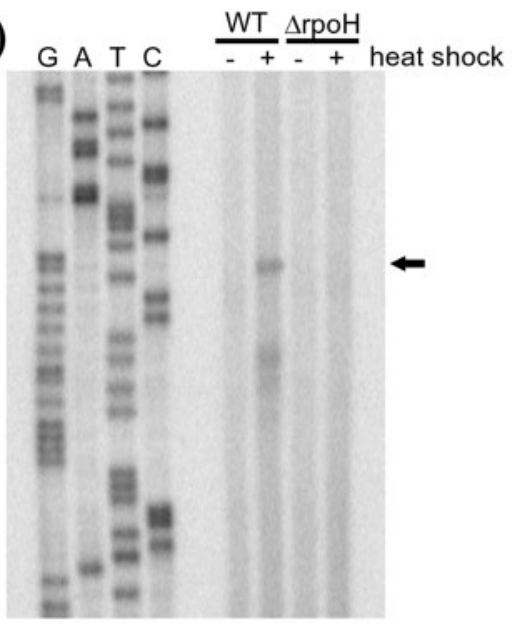

(e)

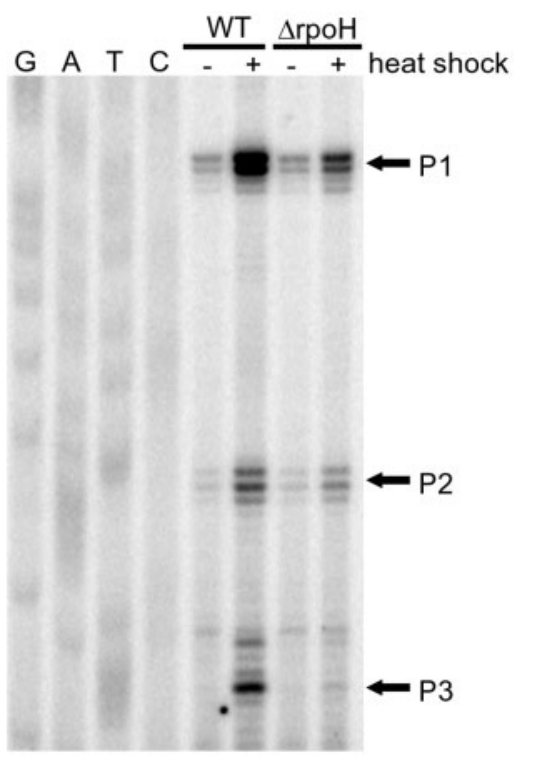

ATCATCCCCTTGAAATCGCTCCGACCATGATTAGGTTAAAG

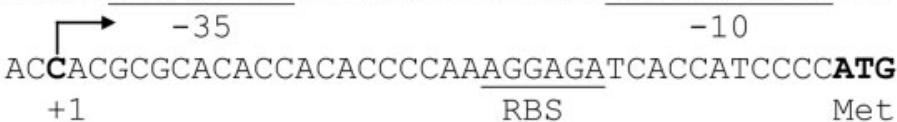

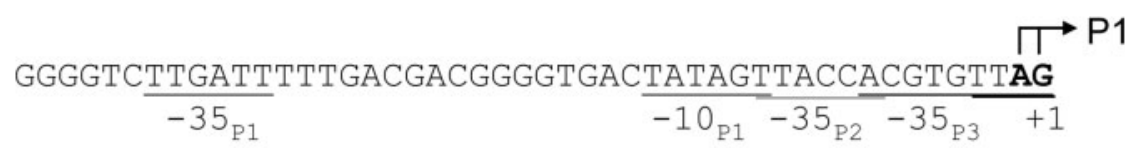

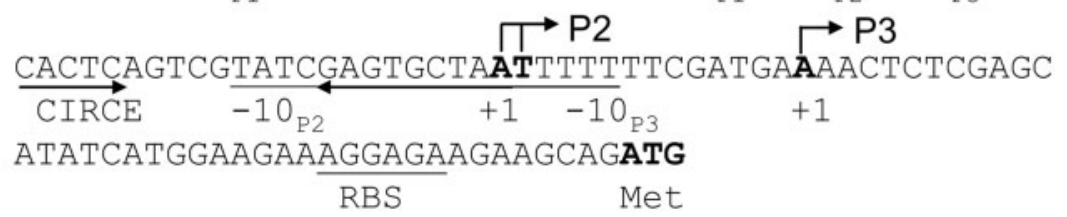

Fig. 3 (continued from facing page). Expression of heat-shock genes. (a) hrcA. (b) grpE. (c) dnaK. (d) htpG. (e) groES. Primer extension assays and their promoter regions are shown. Total RNA was prepared from the wild-type (WT) and the $\mathrm{rpoH}$ mutant $(\mathrm{rpoH})$ strains before $(-)$ and after $(+)$ heat shock. The $5^{\prime}$ ends of mRNA identified by the primer extension assays are indicated by +1 . The putative -35 and -10 elements and putative RBS are underlined. The arrows indicate the putative CIRCE element. The initiation codon is indicated by Met.

$\gamma$-Proteobacteria are absent (data not shown), while the rpoH gene has an RpoH-dependent promoter (Figs 1 and 4 ). Thus, the regulation of rpoH expression in G. sulfurreducens appears to be more closely related to that in $\alpha$-Proteobacteria. However, it is likely that rpoH expression in G. sulfurreducens is more tightly regulated, as G. sulfurreducens $r p o H$ also contains a DNA element identical to the CIRCE consensus sequence (Fig. 1), indicating negative regulation of $r p o H$ expression by HrcA.

\section{Heat-shock promoters in G. sulfurreducens}

The heat-shock promoters in G. sulfurreducens can be classified into four groups: promoters containing $-35 /-10$ elements similar to the RpoH consensus recognition sequences (group 1; grpE P2, dnaK P2 and $h t p G$ ), ones containing both $-35 /-10$ elements similar to the RpoH consensus recognition sequences and the sequence identical to the CIRCE consensus sequence (group 2; rpoH, hrcA P2 and groES P3), ones containing $-35 /-10$ elements similar to the RpoD consensus recognition sequences (group 3; groES P1), and ones containing -35/-10 elements different from the consensus recognition sequences for $\mathrm{RpoH}, \mathrm{RpoD}$ or RpoS (group 4; hrcA P1, grpE P1, dnaK P1 and groES P2). The expression of group 1 during heat-shock response was undetectable in the rpoH mutant, while the expression dependent on the promoters containing the CIRCE 
(a)

rpoH
hrcA P2
htpG
dnaK P2
grpE P2
groES P3
CONSENSUS
E. COli

(b)

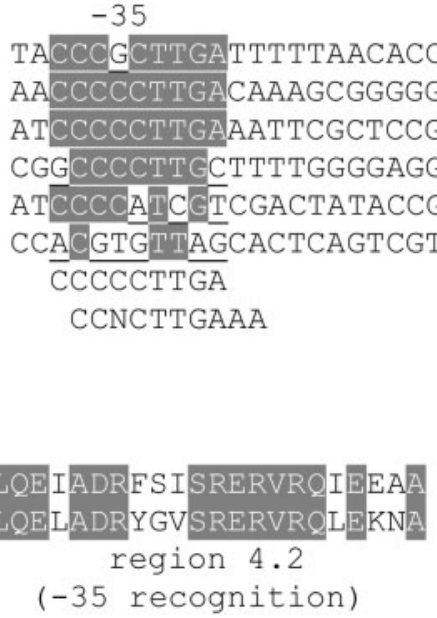

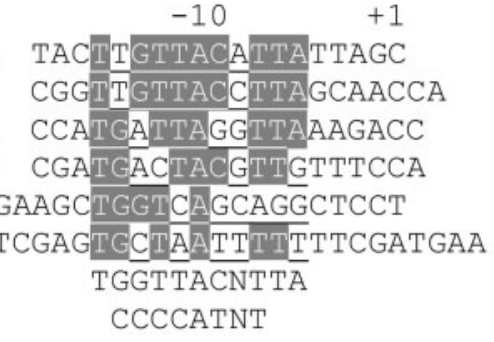

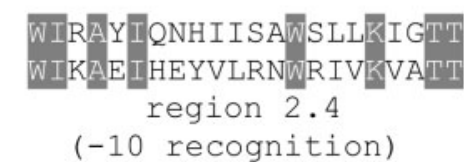

Fig. 4. Heat-shock promoters. (a) Comparison of G. sulfurreducens heat-shock promoters and E. coli RpoH consensus recognition sequences (Gross, 1996; Yura et al., 2000). Nucleotides conserved in more than two promoters are highlighted. (b) Comparison of regions 4.2 and 2.4 of $\mathrm{RpoH}$ from $\mathrm{G}$. sulfurreducens and $E$. coli. Identical amino acid residues are highlighted.

sequence was still observed (Figs 3 and 5), suggesting that the expression of $r p o H, h r c A$ and groES is repressed by the HrcA/CIRCE system. The presence of the $-35 /-10$ elements similar to those in RpoD- or RpoS-dependent promoters suggests the involvement of RpoD and/or RpoS in heat shock. Because there is no apparent sequence similarity among $-35 /-10$ promoter elements in group 4 , it is possible that another transcription factor is involved in heat-shock response transcription.

\section{Phylogenetic perspectives}

The division of $\delta$-Proteobacteria consists of a variety of Gram-negative bacteria including anaerobic metal-reducing (a)

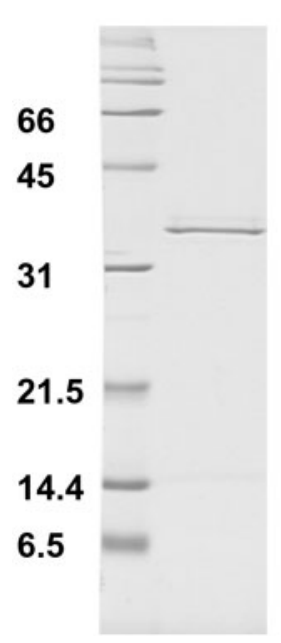

(b)

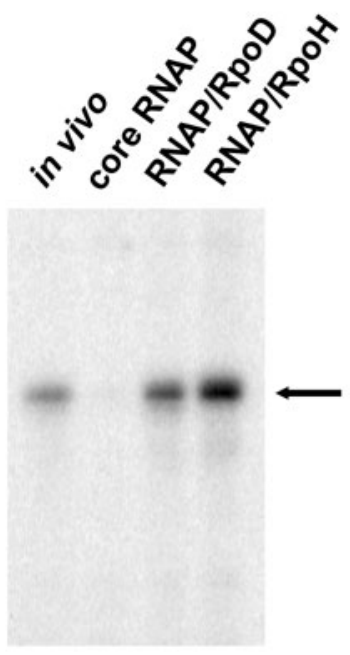

(c)
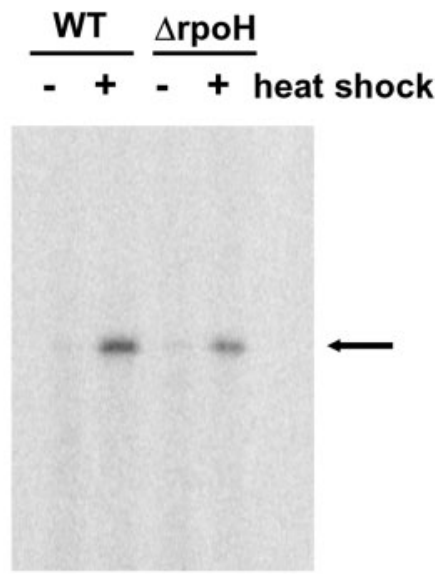

Fig. 5. Transcription of $r p o H$. (a) Purification of G. sulfurreducens RpoH. The sizes of molecular standards are shown in kDa. (b) In vitro transcription. The $r p o H$ promoter was tested as a template with core RNAP, holo RNAP/RpoD and RNAP/RpoH. Transcripts were analysed by primer extension assays with the same primer as used in Fig. 1(a). In vivo RNA was used as a control for the transcription initiation site. (c) In vivo expression. Total RNA was prepared from wild-type (WT) and rpoH mutant $(\Delta \mathrm{rpoH})$ strains before $(-)$ and after $(+)$ heat shock and analysed by primer extension assays with the same primer as used in Fig. 1(a). 
bacteria such as Geobacter and Desulfovibrio species, bacteriolytic Bdellovibrio species, syntrophic bacteria and aerobic developmental myxobacteria. RpoH homologues were identified in other $\delta$-Proteobacteria including $G$. metallireducens (CP000148), D. vulgaris (AE017285), Bdellovibrio bacteriovorus (BX842601), the syntrophic benzoate-oxidizing bacterium Syntrophus aciditrophicus (CP000252), M. xanthus (CP000113), and an anaerobic myxobacterium, A. dehalogenans (CP000251) (www.ncbi.nlm.nih.gov/Genomes). Most of the $\delta$ Proteobacteria described above have a single RpoH homologue, while $M$. xanthus and $A$. dehalogenans have three $\mathrm{RpoH}$ homologues. In addition, $\mathrm{RpoH}$-dependent promoters were predicted to be present in several genes in anaerobic metal-reducing $\delta$-Proteobacteria (Rodionov et al., 2004). Thus, it appears likely that most of the $\delta$ Proteobacteria have RpoH-dependent heat-shock response transcription as found in G. sulfurreducens.

HrcA homologues were identified in other $\delta$-Proteobacteria including G. metallireducens, D. vulgaris, M. xanthus and A. dehalogenans, whereas they are absent from $B$. bacteriovorus and S. aciditrophicus (www.ncbi.nlm.nih.gov/Genomes). In addition, the CIRCE consensus sequence was predicted to be located in several genes from anaerobic metal-reducing $\delta$ Proteobacteria (Rodionov et al., 2004). Thus, the HrcA/ CIRCE negative regulatory system may also be involved in transcription of heat-shock genes in $\delta$-Proteobacteria.

Based on the genomic analyses described above, it appears likely that transcription mechanisms during heat-shock response are diverse in $\delta$-Proteobacteria. Anaerobic metalreducing bacteria utilize both $\mathrm{RpoH}$ as an activator and $\mathrm{HrcA}$ as a repressor for transcription of heat-shock genes. A developmental myxobacterium, $M$. xanthus, seems to contain only the HrcA/CIRCE system. Bacteriolytic and syntrophic microorganisms, B. bacteriovorus and S. aciditrophicus, respectively, appear to possess only $\mathrm{RpoH}$ dependent transcription.

Apparent homologues of other repressors known to be involved in bacterial heat-shock response transcription such as CtsR, HspR and RheA are absent from G. sulfurreducens. However, it is possible that a regulatory system unidentified in other bacteria is present in G. sulfurreducens as well as other $\delta$-Proteobacteria. For instance, $M$. xanthus utilizes the HsfAB two-component system to activate lonD expression upon heat shock (Ueki \& Inouye, 2002).

\section{Conclusions}

The results demonstrate that the heat-shock sigma factor, $\mathrm{RpoH}$, is essential for adaptation to a higher temperature in G. sulfurreducens. Furthermore, it is most likely that the $\mathrm{HrcA} / \mathrm{CIRCE}$ repression system is also involved in heatshock response transcription in G. sulfurreducens. Taken together with the genomic information, the mechanisms of heat-shock response transcription appear to be diversified in the Gram-negative $\delta$-Proteobacteria. Temperature is one of important environmental factors that influence microbial activities in the subsurface. This study will serve as a foundation for further characterization of Geobacter species in adaptation to different temperatures, which should allow optimization of conditions for applications of Geobacter species to bioremediation and electricity production.

\section{ACKNOWLEDGEMENTS}

This work was supported by the Genomics: GTL program of the Office of Science (BER), US Department of Energy, Grant no. DE-FC0220ER63446. We thank L. DiDonato for critical reading of the manuscript.

\section{REFERENCES}

Arrigo, A. P. \& landry, J. (1994). The Biology of Heat Shock Proteins and Molecular Chaperones. Cold Spring Harbor, NY: Cold Spring Harbor Laboratory.

Bond, D. R. \& Lovley, D. R. (2003). Electricity production by Geobacter sulfurreducens attached to electrodes. Appl Environ Microbiol 69, 1548-1555.

Bond, D. R., Holmes, D. E., Tender, L. M. \& Lovley, D. R. (2002). Electrode-reducing microorganisms that harvest energy from marine sediments. Science 295, 483-485.

Caccavo, F., Jr, Lonergan, D. J., Lovley, D. R., Davis, M., Stolz, J. F. \& McInerney, M. J. (1994). Geobacter sulfurreducens sp. nov., a hydrogen- and acetate-oxidizing dissimilatory metal-reducing microorganism. Appl Environ Microbiol 60, 3752-3759.

Chhabra, S. R., He, Q., Huang, K. H., Gaucher, S. P., Alm, E. J., He, Z., Hadi, M. Z., Hazen, T. C., Wall, J. D. \& other authors (2006). Global analysis of heat shock response in Desulfovibrio vulgaris Hidenborough. J Bacteriol 188, 1817-1828.

Coppi, M. V., Leang, C., Sandler, S. J. \& Lovley, D. R. (2001). Development of a genetic system for Geobacter sulfurreducens. Appl Environ Microbiol 67, 3180-3187.

Gross, C. A. (1996). Function and regulation of the heat shock proteins. In Escherichia coli and Salmonella: Cellular and Molecular Biology, 2nd edn, pp. 1382-1399. Edited by F. C. Neidhardt and others. Washington, DC: American Society for Microbiology.

Hanahan, D. (1983). Studies on transformation of Escherichia coli with plasmids. J Mol Biol 166, 557-580.

Harley, C. B. \& Reynolds, R. P. (1987). Analysis of E. coli promoter sequences. Nucleic Acids Res 15, 2343-2361.

Hawley, D. K. \& McClure, W. R. (1983). Compilation and analysis of Escherichia coli promoter DNA sequences. Nucleic Acids Res 11, 2237-2255.

Hecker, M., Schumann, W. \& Volker, U. (1996). Heat-shock and stress response in Bacillus subtilis. Mol Microbiol 19, 417-428.

Hengge-Aronis, R. (2002). Recent insights into the general stress response regulatory network in Escherichia coli. J Mol Microbiol Biotechnol 4, 341-346.

Kovach, M. E., Phillips, R. W., Elzer, P. H., Roop, R. M., II \& Peterson, K. M. (1994). pBBR1MCS: a broad-host-range cloning vector. BioTechniques 16, 800-802.

Lindquist, S. \& Craig, E. A. (1998). The heat-shock proteins. Annu Rev Genet 22, 631-677.

Lloyd, J. R. \& Lovley, D. R. (2001). Microbial detoxification of metals and radionuclides. Curr Opin Biotechnol 12, 248-253. 
Lovley, D. R. (1997). Microbial Fe(III) reduction in subsurface environments. FEMS Microbial Rev 20, 305-313.

Lovley, D. R. (2003). Cleaning up with genomics: applying molecular biology to bioremediation. Nat Rev Microbiol 1, 35-44.

Lovley, D. R. (2006a). Microbial fuel cells: novel microbial physiologies and engineering approaches. Curr Opin Biotechnol 17, 327-332. Lovley, D. R. (2006b). Bug juice: harvesting electricity with microorganisms. Nat Rev Microbiol 4, 497-508.

Lovley, D. R. \& Coates, J. D. (1997). Bioremediation of metal contamination. Curr Opin Biotechnol 8, 285-289.

Lovley, D. R. \& Coates, J. D. (2000). Novel forms of anaerobic respiration of environmental relevance. Curr Opin Microbiol 3, 252-256.

Lovley, D. R., Holmes, D. E. \& Nevin, K. P. (2004). Dissimilatory $\mathrm{Fe}(\mathrm{III})$ and $\mathrm{Mn}(\mathrm{IV})$ reduction. Adv Microb Physiol 49, 219-286.

Marx, C. J. \& Lidstrom, M. E. (2001). Development of improved versatile broad-host-range vectors for use in methylotrophs and other Gram-negative bacteria. Microbiology 147, 2065-2075.

Methé, B. A., Nelson, K. E., Eisen, J. A., Paulsen, I. T., Nelson, W., Heidelberg, J. F., Wu, D., Wu, M., Ward, N. \& other authors (2003). Genome of Geobacter sulfurreducens: metal reduction in subsurface environments. Science 302, 1967-1969.

Miller, J. H. (1972). Experiments in Molecular Genetics. Cold Spring Harbor, NY: Cold Spring Harbor Laboratory.

Mogk, A., Homuth, G., Scholz, C., Kim, L., Schmid, F. X. \& Schumann, W. (1997). The GroE chaperonin machine is a major modulator of the CIRCE heat shock regulon of Bacillus subtilis. EMBO J 16, 4579-4590.

Nakahigashi, K., Yanagi, H. \& Yura, T. (1995). Isolation and sequence analysis of rpoH genes encoding $\sigma^{32}$ from gram negative bacteria: conserved mRNA and protein segments for heat shock regulation. Nucleic Acids Res 23, 4384-4390.

Nakahigashi, K., Ron, E. Z., Yanagi, H. \& Yura, T. (1999). Differential and independent roles of a $\sigma^{32}$ homolog $(\mathrm{RpoH})$ and an HrcA repressor in the heat shock response of Agrobacterium tumefaciens. J Bacteriol 181, 7509-7515.

Narberhaus, F. (1999). Negative regulation of bacterial heat shock genes. Mol Microbiol 31, 1-8.

Narberhaus, F., Giebeler, K. \& Bahl, H. (1992). Molecular characterization of the dnaK gene region of Clostridium acetobutylicum, including grpE, dnaJ, and a new heat shock gene. J Bacteriol 174, 3290-3299.

Narberhaus, F., Krummenacher, P., Fischer, H. M. \& Hennecke, H. (1997). Three disparately regulated genes for $\sigma^{32}$-like transcription factors in Bradyrhizobium japonicum. Mol Microbiol 24, 93-104.

Núñez, C., Adams, L., Childers, S. \& Lovley, D. R. (2004). The RpoS sigma factor in the dissimilatory $\mathrm{Fe}(\mathrm{III})$-reducing bacterium Geobacter sulfurreducens. J Bacteriol 186, 5543-5546.

Reisenauer, A., Mohr, C. D. \& Shapiro, L. (1996). Regulation of the heat shock $\sigma^{32}$ homolog in Caulobacter crescentus. J Bacteriol 178, 1919-1927.

Riggs, D. L., Cox, M. B., Cheung-Flynn, J., Prapapanich, V., Carrigan, P. E. \& Smith, D. F. (2004). Functional specificity of co-chaperone interactions with Hsp90 client proteins. Crit Rev Biochem Mol Biol 39, 279-295.

Roberts, R. C., Toochinda, C., Avedissian, M., Baldini, R. L., Gomes, S. L. \& Shapiro, L. (1996). Identification of a Caulobacter crescentus operon encoding $h r c A$, involved in negatively regulating heat-inducible transcription, and the chaperone gene grpE. J Bacteriol 178, 1829-1841.

Rodionov, D. A., Dubchak, I., Arkin, A., Alm, E. \& Gelfand, M. S. (2004). Reconstruction of regulatory and metabolic pathways in metal-reducing $\delta$-proteobacteria. Genome Biol 5, R90.
Rosen, R. \& Ron, E. Z. (2002). Proteome analysis in the study of the bacterial heat-shock response. Mass Spectrom Rev 21, 244265.

Sandler, S. J. \& Clark, A. J. (1994). RecOR suppression of recF mutant phenotypes in Escherichia coli K-12. J Bacteriol 176, 36613672 .

Schulz, A. \& Schumann, W. (1996). hrcA, the first gene of the Bacillus subtilis dnaK operon encodes a negative regulator of class I heat shock genes. J Bacteriol 178, 1088-1093.

Schumann, W. (2000). Function and regulation of temperatureinducible bacterial proteins on the cellular metabolism. Adv Biochem Eng Biotechnol 67, 1-33.

Schumann, W. (2003). The Bacillus subtilis heat shock stimulon. Cell Stress Chaperones 8, 207-217.

Servant, P. \& Mazodier, P. (2001). Negative regulation of the heat shock response in Streptomyces. Arch Microbiol 176, 237-242.

Spohn, G., Danielli, A., Roncarati, D., Delany, I., Rappuoli, R. \& Scarlato, V. (2004). Dual control of Helicobacter pylori heat shock gene transcription by HspR and HrcA. J Bacteriol 186, 2956-2965.

Taylor, W. E., Straus, D. B., Grossman, A. D., Burton, Z. F., Gross, C. A. \& Burgess, R. R. (1984). Transcription from a heat-inducible promoter causes heat shock regulation of the sigma subunit of $E$. coli RNA polymerase. Cell 38, 371-381.

Ueki, T. \& Inouye, S. (2001). SigB, SigC, and SigE from Myxococcus xanthus homologues to sigma 32 are not required for heat shock response but for multicellular differentiation. J Mol Microbiol Biotechnol 3, 287-293.

Ueki, T. \& Inouye, S. (2002). Transcriptional activation of a heat-shock gene, lonD, of Myxococcus xanthus by a two component histidineaspartate phosphorelay system. J Biol Chem 277, 6170-6177.

Ueki, T. \& Inouye, S. (2005). Identification of a gene involved in polysaccharide export as a transcription target of FruA, an essential factor for Myxococcus xanthus development. J Biol Chem 280, 32279-32284.

Wetzstein, M., Volker, U., Dedio, J., Lobau, S., Zuber, U., Schiesswohl, M., Herget, C., Hecker, M. \& Schumann, W. (1992). Cloning, sequencing, and molecular analysis of the dnaK locus from Bacillus subtilis. J Bacteriol 174, 3300-3310.

Wu, J. \& Newton, A. (1996). Isolation, identification, and transcriptional specificity of the heat shock sigma factor $\sigma^{32}$ from Caulobacter crescentus. J Bacteriol 178, 2094-2101.

Yan, B., Núñez, C., Ueki, T., Esteve-Núñez, A., Puljic, M., Adkins, R. M., Methé, B. A., Lovley, D. R. \& Krushkal, J. (2006). Computational prediction of RpoS and RpoD regulatory sites in Geobacter sulfurreducens using sequence and gene expression information. Gene 384, 73-95.

Young, J. C., Agashe, V. R., Siegers, K. \& Hartl, F. U. (2004). Pathways of chaperone-mediated protein folding in the cytosol. Nat Rev Mol Cell Biol 5, 781-791.

Yura, T., Kanemori, M. \& Morita, M. T. (2000). The heat shock response: regulation and function. In Bacterial Stress Responses, pp. 3-18. Edited by G. Storz \& R. Hengge-Aronis. Washington, DC: American Society for Microbiology.

Zhang, X., Beuron, F. \& Freemont, P. S. (2002). Machinery of protein folding and unfolding. Curr Opin Struct Biol 12, 231238.

Zuber, U. \& Schumann, W. (1994). CIRCE, a novel heat-shock element involved in regulation of heat-shock operon dnaK of Bacillus subtilis. J Bacteriol 176, 1359-1363.

Edited by: M. Hecker 